ISSN: $1412-8837$

\title{
ANALISIS PENDAPATAN DAN PEMASARAN USAHATANI BROKOLI (Brassica oleracea L.) DI DESA MUARA PERIKAN KECAMATAN PAGARALAM SELATAN KOTAMADYA PAGARALAM
}

\author{
INCOME AND MARKETING ANALYSIS OF BROCCOLI (Brassica \\ oleracea L.) FARM IN DESA MUARA PERIKAN SUB-DISTRICT OF \\ SOUTH PAGARALAM, DISTRICT OF PAGARALAM
}

\author{
Denny Wijaya, Satria Putra Utama dan Indra Cahyadinata \\ Jurusan Sosial Ekonomi Pertanian Fakultas Pertanian, Universitas Bengkulu
}

\begin{abstract}
This research was conducted with the purpose to: (1) calculate farm income of broccoli, (2) investigate marketing channels of broccoli and (3) calculate its marketing margin. Research area is determined purposively, i.e., Muara Perikan Village Subdistrict South Pagaralam. Respondents of broccoli farmers are censused involving 14 farmers while marketing institutions are determined with Snowball Sampling. The research showed that averaged farm income is equal to Rp.11.026.213/farming, or Rp.34.852.536/Ha and efficiency of farm broccoli is equal to 3,56. This means that broccoli farming in research area is efficient. In terms of marketing channel, three marketing channels were found. In this study, only two channels were studied. In the first marketing channels, farmers share was high at $66.67 \%$ of the final sale price merchants. Total margin from one marketing channel activity of Rp. 3000, the total profit margin of $\mathrm{Rp}$. 2295.26. In the second channels, the percentage share of farmers was $51.43 \%$, with marketing margin of Rp. 5666.67 and the total profit of Rp. 4673.07
\end{abstract}

Keywords: broccoli, marketing channel, margin

\section{PENDAHULUAN}

Dalam rangka peningkatan produksi pertanian pada periode lima Tahun ke depan (2010-2014), disamping prioritas pada lima komoditas pangan utama (Padi., Jagung, Kedelai, Gula dan Sapi) juga akan dikembangkan komoditas lainnya, seperti; hortikultura, perkebunan dan peternakan. Sumatera Selatan merupakan salah satu provinsi yang diprioritaskan dalam pengembangan kawasan hortikultura yang memiliki kondisi agroklimat dan lahan untuk pengembangan komoditi hortikultura diantaranya buah-buahan dan sayuran. 
Pengembangan intensif hortikultura terdapat di Kota Pagaralam. Pendampingan Program Strategis Departemen Pertanian akan pengembangan kawasan hortikultura di dua Kabupaten/Kota yaitu: Kota Pagaralam merupakan kawasan pengembangan intensif dan Kota Prabumulih masih merupakan inisiasi.

Sebagai daerah yang didominasi dataran tinggi dengan kondisi lahan yang relatif subur, Kota Pagaralam pun sangat potensial untuk pengembangan agrobisnis komoditi sayuran. Kecamatan yang menjadi unggulan produksi dan sayuran adalah Kecamatan Dempo Utara dan Pagaralam Selatan. Kedua Kecamatan tersebut terletak di kaki Gunung Dempo sehingga sangat cocok untuk ditanami sayuran. Salah satu komoditi unggulan beberapa tahun terakhir di Kecamatan Pagaralam Selatan, khususnya Desa Muara Perikan adalah brokoli.

Dari data statistik Kota Pagaralam (BPS, 2009) secara keseluruhan, brokoli memang bukan merupakan produksi tertinggi di Kota Pagaralam. Pada akhir tahun 2009, tercatat bahwa produk sayuran didominasi komoditi kubis, sebanyak 15.120 ton, disusul sawi, 7.125 ton, Wortel, 6.450 ton, bawang daun, 2.330 ton, tomat, 2.010 ton. Secara keseluruhan luas panen tanaman sayuran mencapai 2.315 Hektar dengan produksi mencapai 40.838 ton atau rata-rata 17,64 ton/ha. Sedangkan produksi brokoli bukan merupakan produksi tertinggi di Kota Pagaralam. Produksinya pun hanya mencapai 195 ton artinya masih jauh di bawah tanaman yang lain. Total produksi yang masih di bawah komoditi lain ini disebabkan tanaman brokoli masih terpusat di Kecamatan Pagaralam Selatan, khususnya Desa Muara Perikan. Penelitian mengenai brokoli ini secara sengaja dipilih dikarenakan komoditi ini terbilang baru (4 tahun) di daerah penelitian. Sehingga tepat untuk melakukan suatu analisa mengenai usahatani yang dilakukan dari segi pendapatan para petani brokoli sampai dengan analisis pemasaran brokoli di Desa Muara Perikan Berdasarkan hal tersebut, maka peneliti merasa perlu untuk menganalisis hal yang berkaitan dengan pendapatan, bentuk saluran pemasaran, dan marjin pemasaran brokoli di Desa Muara Perikan Pagaralam Selatan, Kota Pagaralam.

Dari uraian latar belakang di atas, ada tiga tujuan yang ingin dicapai dalam penelitian ini. Pertama, penelitian ini ditujukan untuk menghitung besarnya pendapatan usahatani brokoli di Desa Muara Perikan Kecamatan Pagaralam Selatan. Tujuan ke dua adalah mengidentifikasi bentuk saluran pemasaran brokoli serta menghitung besarnya marjin pemasaran brokoli di Desa Muara Perikan Kecamatan Pagaralam Selatan sebagai tujuan ke tiga.

\section{METODE PENELITIAN}

\section{Lokasi dan Waktu Penelitian}

Brokoli merupakan komoditi baru di Pagaralam, dalam pengembangannya, brokoli secara intensif dikembangkan di Kecamatan 
Pagaralam Selatan. Desa Muara Perikan merupakan satu-satunya daerah yang melakukan kegiatan usahatani brokli di Kecamatan Pagaralam Selatan. Selain itu pemilihan lokasi penelitian ini didasarkan atas keterjangkauan peneliti menuju daerah penelitian. Penelitian ini dilakukan pada tanggal 1 hingga 4 Mei 2012.

\section{Metoda penentuan Sampel}

Terdapat 11 orang petani brokoli yang menggarap lahannya sendiri, dan 3 lainnya menyewa lahan. Dengan mempertimbangkan tingkat populasi, maka metode sensus dilakukan dalam pengambilan sampel. Untuk responden saluran pemasaran, responden pedagang pengumpul desa sebanyak 3 orang, pedagang pasar sebanyak 5 orang, dan pedagang pengecer akhir sebanyak 6 orang.

\section{Metoda Pengumpulan Data}

Data yang digunakan pada penelitian ini terdiri dari data primer dan data sekunder. Data primer merupakan hasil wawancara langsung dengan petani responden dengan menggunakan daftar pertanyaan (kuesioner) yang telah dipersiapkan. Data sekunder merupakan data baku pelengkap yang diperoleh dari instansi atau kantor dinas yang terkait dengan penelitian ini.

\section{Metoda Analisa Data}

Untuk menghitung penerimaan usahatani brokoli digunakan rumus sebagai berikut (Soekartawi,1995):

$$
\mathbf{T R}=\mathbf{Q} \times \mathbf{P}
$$

dimana TR adalah Penerimaan total (Rp), Q adalah Jumlah produksi yang dihasilkan $(\mathrm{kg})$, dam $\mathrm{P}$ adalah Harga $(\mathrm{Rp})$.

Besarnya pendapatan yang diperoleh petani brokoli dihitung dengan menggunakan rumus sebagai berikut: (Soekartawi, 1995)

$$
\begin{array}{ll}
\mathrm{Pd} & =\mathrm{TR}-\mathrm{TC} \\
\mathrm{TR} & =\mathrm{Q} \times \mathrm{Pq} \\
\mathrm{TC} & =\mathrm{VC}+\mathrm{FC}
\end{array}
$$

dimana TC adalah biaya total (Total Cost) atau total pengeluaran usahatani Brokoli (Rp/UT/Ha), VC adalah biaya variabel usahatani brokoli (variable cost) ( $\mathrm{Rp} / \mathrm{UT} / \mathrm{Ha}$ ), FC adalah biaya tetap usahatani brokoli (fixed cost) (Rp/UT/Ha), TR adalah total penerimaan usahatani brokoli $(\mathrm{Rp} / \mathrm{UT} / \mathrm{Ha}), \mathrm{Q}$ adalah jumlah produksi brokoli $(\mathrm{Kg} / \mathrm{UT} / \mathrm{Ha}), \mathrm{Pq}$ adalah Harga Brokoli $(\mathrm{Rp} / \mathrm{Kg})$, Pd adalah pendapatan usahatani brokoli (Rp/UT/Ha)

Efisiensi Usahatani diestimasi dengan menggunakan rumus sebagai berikut: 


$$
R / C \text { ratio }=\frac{\text { TotalRevenue }(\mathrm{TR})}{\text { TotalCost }(\mathrm{TC})}
$$

untuk mengukur tingkat efisiensi usahatani brokoli digunakan kriteria: (a) jika $\mathrm{R} / \mathrm{C}$ ratio $>1$, usahatani efisien, (b) jika $\mathrm{R} / \mathrm{C}$ ratio $=1$, usahatani impas, dan (c) jika $\mathrm{R} / \mathrm{C}$ ratio $<1$, usahatani tidak efisien.

Dalam mengidentifikasi saluran pemasaran brokoli dianalisis secara deskriptif dengan menggambarkan pola saluran pemasaran brokoli di Desa Muara Perikan, Pagaralam Selatan dengan metode Snow Ball yaitu menganalisis satu persatu pelaku pasar yang berkaitan dengan pemasaran brokoli dari produsen, pedagang perantara hingga konsumen akhir.

Untuk menghitung margin pemasaran pada masing-masing lembaga pemasaran brokoli, maka digunakan rumus (Anindita, 2004 dan Lubis, 2007):

$$
\text { Mji } \quad=\text { Psi }- \text { Pbi }
$$

Margin pemasaran dapat juga dihitung dengan menjumlahkan biaya dan keuntungan pemasaran brokoli dan dapat ditulis:

Mji $=b t i+n i$

Keuntungan lembaga pemasaran brokoli dihitung menggunakan rumus:

$$
\pi_{i}=M_{j i}-b_{t i}
$$

Sehingga total margin adalah:

$$
M_{j}=\sum_{i=1}^{n} M_{j i}
$$

dimana Mjimerupakan Margin pemasaran pada lembaga pemasaran ke-i, $\mathrm{Mj}$ merupakan Total margin pemasaran brokoli, Psi merupakan Harga jual lembaga pemasaran tingkat ke-i (Rp/Kg), PbimerupakanHarga beli lembaga pemasaran tingkat ke-i $(\mathrm{Rp} / \mathrm{Kg})$, bti merupakan Biaya lembaga pemasaran brokoli tingkat ke-i, $\pi_{\mathrm{i}}$ merupakan Keuntungan lembaga pemasaran tingkat ke-i, dan i merupakan $1,2,3, \ldots, \ldots, \mathrm{n}$

Efisiensi Pemasaran sering diukur dengan melihat persentase keuntungan terhadap biaya pemasaran, atau diukur dengan menggunakan rumus rasio keuntungan terhadap biaya $=\pi_{i} / C_{i} \times 100 \%$ (Hanifah dan Saefudin,1983 dalam Lubis, 2007). Dari rasio ini, apabila $\pi_{i} / C_{i}>0$, maka kegiatan pemasaran sudah efisien, sedangkan jika $\pi_{i} / C_{i}<0$, maka kegiatan pemasaran tidak efisien. Dimana, пі merupakan keuntungan tingkat pedagang di saluran ke-i, Ci merupakan biaya yang dikeluarkan pedagang di saluran ke-i, i merupakan 1, 2, $3, \ldots, n$.

Untuk mengetahui saluran pemasaran yang lebih efisien, kita perlu meninjau dari sudut pandang lembaga pemasaran dan sudut pandang 
konsumen. Dari sudut pandang lembaga lembaga pemasaran, efisiensi telah tercapai apabila didapat keuntungan yang kompetitif. Dari sudut pandang konsumen, dikatakan efisien apabila dapat memberikan kepuasan kepada konsumen dari barang yang dibutuhkan baik dalam waktu, bentuk, tempat, kualitas dan harga.

\section{HASIL DAN PEMBAHASAN}

\section{Karakteristik Responden}

Umur petani responden brokoli di daerah penelitian mayoritas berusia 3540 tahun yaitu sebanyak 7 orang atau 50 persen. Secara keseluruhan, baik petani brokli di daerah penelitian berada pada usia yang produktif (kurang dari 50 tahun). Pada usia yang produktif petani akan menghasilkan produktivitas kerja yang maksimal. Menurut Mubyarto (1989), petani yang berada pada usia produktif akan memberikan hasil kerja yang maksimal.

Secara umum tingkat pendidikan petani brokoli, mengenyam pendidikan setara Sekolah Lanjutan Tingkat Pertama (SLTP) atau 7 hingga 9 tahun sebesar 42,86 persen atau sebanyak 6 orang. Sebanyak 35,71 persen mengenyam pendidikan formal Sekolah Dasar (SD) dan sisanya pernah mengenyam pendidikan Sekolah Lanjutan Tingkat Atas (SLTA), yaitu sebanyak 3 orang atau 21,43 persen.

Hasil penelitian menunjukkan rata-rata petani responden telah lama berprofesi sebagai petani Sayuran. Namun untuk usahatani brokoli, para petani rata-rata memulainya pada tingga hingga empat tahun terakhir, yaitu mencapai 8 orang atau 57,15 persen. Hanya terdapat 1 responden yang melakoni usahatani brokoli ini dalam dua tahun terakhir, dan sebanyak 35,71 persen atau 5 orang lainnya sudah melakoni usahatani brokoli ini selama lima tahun. Hal ini menunjukkan bahwa usahatani brokoli ini terbilang suatu inovasi baru yang diadopsi para petani di Desa Muara Perikan ini.

Sebagian besar responden petani brokoli memiliki jumlah tanggungan keluarga sebanyak 3 hingga 4 orang, yaitu mencapai 64,29 persen. Terdapat 3 responden atau 21,43 persen yang memiliki jumlah tanggungan keluarga sebanyak 2 orang. Sebanyak 2 responden responden atau 14,28 persen mempunyai jumlah anggota keluarga 5 orang.

Dari hasil penelitian, rata-rata responden dalam hal kepemilikan lahan adalah lahan milik sendiri, sebanyak 11 orang atau 78,57 persen. Sementara sisanya sebanyak 3 responden atau 21,43 persen merupakan petani lahan sewaan, petani penyewa lahan melakukan usahatani mereka dengan sistem bagi hasil yang telah disepakati oleh pemilik lahan.

Luas lahan rata-rata usahatani brokoli di daerah penelitian adalah ratarata 0,34 hektar. Sebagian besar petani brokoli memiliki luasan areal usahatani $\leq$ 0,25 dan 0,26-0,5 hektar yaitu masing-masing sebanyak 42,86 persen. Hanya sebagian kecil saja petani brokoli yang mengusahakan usahatani di luasan lahan 
$\geq 0,51$ hektar yakni 14,28 persen. Luas lahan yang ditanam akan berpengaruh terhadap peningkatan produksi usahatani. Namun peningkatan produksi ini juga disesuaikan dengan penggunaan produksi yang tepat dan sesuai dengan keadaan lingkungan.

Tabel 1. Karakteristik Responden Petani Brokoli di Desa Muara Perikan

\begin{tabular}{|c|c|c|c|c|}
\hline \multirow[b]{2}{*}{ No. } & \multirow[b]{2}{*}{ Karakteristik Responden } & \multicolumn{2}{|c|}{ Brokoli } & \multirow[b]{2}{*}{ Rata-rata } \\
\hline & & $\begin{array}{l}\text { Jumlah } \\
\text { (orang) }\end{array}$ & $\begin{array}{c}\text { Persentase } \\
(\%)\end{array}$ & \\
\hline \multirow[t]{4}{*}{1.} & Umur (tahun) & & & \\
\hline & $29-34$ & 3 & 21,43 & \\
\hline & $35-40$ & 7 & 50 & 38.07 \\
\hline & $41-46$ & 4 & 28,57 & \\
\hline \multirow[t]{4}{*}{2.} & Pendidikan formal (tahun) & & & \\
\hline & $4-6$ & 5 & 35,71 & \\
\hline & 7-9 & 6 & 42,86 & 8.4 \\
\hline & $10-12$ & 3 & 21,43 & \\
\hline \multirow[t]{4}{*}{3.} & Lama berusahatani (tahun) & & & \\
\hline & $\leq 2$ & 1 & 7,14 & \\
\hline & $3-4$ & 8 & 57,15 & 4.07 \\
\hline & $\geq 5$ & 5 & 35,71 & \\
\hline \multirow[t]{4}{*}{4.} & Jumlah tanggungan keluarga (orang) & & & \\
\hline & $\leq 2$ & 3 & 21,43 & \\
\hline & $3-4$ & 9 & 64,29 & 3.29 \\
\hline & $\geq 5$ & 2 & 14,28 & \\
\hline \multirow[t]{3}{*}{5.} & Status kepemilikan lahan & & & \\
\hline & Milik Sendiri & 11 & 78,57 & \\
\hline & Sewa & 3 & 21,43 & \\
\hline \multirow[t]{4}{*}{6.} & Luas lahan (Ha) & & & \\
\hline & $\leq 0.25$ & 6 & 42,86 & \\
\hline & $0.26-0.5$ & 6 & 42,86 & 0.34 \\
\hline & $\geq 0.51$ & 2 & 14,28 & \\
\hline
\end{tabular}

Sumber: Data Primer tahun 2012, diolah.

\section{Biaya Produksi Usahatani Brokoli}

Biaya produksi merupakan biaya yang dikeluarkan oleh petani dalam kegiatan usahatani brokoli. Biaya-biaya yang dikeluarkan petani dalam berusahatani brokoli terdiri dari biaya benih, mulsa, pupuk, pestisida, penyusutan alat-alat pertanian, tenaga kerja, sewa lahan, dan pajak lahan. Selanjutnya biaya-biaya tersebut dikelompokkan ke dalam biaya produksi variabel dan biaya tetap yang dikeluarkan oleh petani. Biaya produksi merupakan penjumlahan dari seluruh biaya variabel dan biaya tetap. Dengan lebih rinci biaya-biaya tersebut dapat dilihat pada Tabel 2. 
Tabel 2. Rata-rata Total Biaya Produksi Pada Usahatani Brokoli di Desa Muara Perikan

\begin{tabular}{lrrr}
\hline Uraian & $(\mathrm{Rp} / \mathrm{UT})$ & \multicolumn{1}{c}{$(\mathrm{Rp} / \mathrm{Ha})$} & \multicolumn{1}{c}{$(\%)$} \\
\hline Biaya Variabel & & & \\
- Benih & $1.568 .928,57$ & $4.774 .547,25$ & 29,06 \\
- Mulsa & $2.278 .571,43$ & $6.773 .605,81$ & 41,83 \\
- Pupuk & $309.857,14$ & $799.921,27$ & 5,18 \\
- Pestisida & $242.857,14$ & $782.972,91$ & 4,52 \\
- Tenaga Kerja Luar Keluarga & $13.928,57$ & $25.903,88$ & 0,16 \\
- Tenaga Kerja Dalam Keluarga & $801.428,57$ & $2.500 .925,16$ & 15,07 \\
Biaya Tetap & & & \\
- Penyusutan Peralatan & $47.739,22$ & $160.055,34$ & 0,95 \\
- Sewa Lahan & $249.937,50$ & $452.546,30$ & 3,19 \\
- Pajak Lahan & $2.159,06$ & $7.683,71$ & 0,04 \\
\hline Jumlah & $5.318 .565,09$ & $15.920 .943,02$ & $100 \%$ \\
\hline
\end{tabular}

Sumber: Data Primer 2012, diolah

Rata-rata total biaya yang dikeluarkan oleh petani brokoli di daerah penelitian adalah sebesar Rp. 5.318.565/UT atau Rp. 15.920.943/Ha. Dari total biaya tersebut, biaya mulsa memberikan proporsi 41,83 persen yaitu sebesar Rp. 2.278.571/UT atau Rp. 6.773.606/Ha. Besarnya proporsi biaya mulsa dikarenakan mahalnya harga mulsa tersebut. Untuk 29,06 persen atau sebesar Rp. 1.568.929/UT atau Rp. 4.774.547 merupakan biaya benih yang dibeli petani dalam melakukan usahatani brokoli, mahalnya harga benih dan jarak tamah yang terbilang rapat menyebabkan proporsi untuk biaya benih cukup besar.

Untuk pengeluaran faktor produksi terkecil adalah biaya pajak lahan yaitu sebesar Rp. 2.159/UT atau Rp. 7.683/Ha dengan proporsi biaya 0.04 persen. Kecilnya biaya pajak ini disebabkan lahan usahatani yang relatif kecil, sehingga biaya pajak yang diperhitungkan pun tidak terlalu besar. Bila dibandingkan dengan penelitian Nugraha (2009) untuk luas lahan 1 Ha total biaya untuk usahatani brokoli di Desa Cibodas, Bogor Barat mencapai Rp. 35.640.307 artinya untuk total biaya yang dikeluarkan petani brokoli di daerah penelitian jauh lebih kecil dibandingkan di Desa Cibodas. Hal ini disebabkan penggunaan tenaga kerja di Desa Cibodas jauh lebih besar.

\section{Analisa Pendapatan Usahatani}

Salah satu penentu tinggi rendahnya produksi pertanian adalah penerapan teknologi, indikator dari hal tersebut adalah penggunaan sarana produksi pertanian dan teknik budidaya, seperti penggunaan benih, mulsa, pestisida, dan jarak tanam. Adapun untuk rata-rata penerimaan dan pendapatan dari usahatani brokoli di Desa Muara Perikan secara rinci dapat dilihat dalam Tabel 3. 
Tabel 3. Rata-rata Total Penerimaan, Total Biaya, Pendapatan dan R/C ratio Usahatani Brokoli di Desa Muara Perikan

\begin{tabular}{lrr}
\hline \multicolumn{1}{c}{ Uraian } & Jumlah (UT) & Jumlah (Ha) \\
\hline Total Penerimaan $(\mathrm{Rp})$ & $18.723 .428,57$ & $55.121 .396,76$ \\
Biaya Total (Rp) & $5.318 .565,09$ & $15.920 .943,02$ \\
Pendapatan (Rp) & $11.026 .212,78$ & $34.852 .536,30$ \\
R/C ratio & 3,56 & 3,56 \\
\hline
\end{tabular}

Sumber: Data Primer 2012, diolah

Produksi total yang dihasilkan oleh petani sebagian besar dijual, dan sebagian kecil lagi dikonsumsi. Dari rata-rata total produksi $3.120,57 \mathrm{~kg} / \mathrm{UT}$, hanya $3.11 \mathrm{~kg}$ yang dikonsumsi petani dalam satu kali musim tanam. Pendapatan usahatani sangat ditentukan oleh penerimaan dari produksi yang dihasilkan dan biaya-biaya yang dikeluarkan. Pendapatan usahatani diperoleh dari selisih antara penerimaan dan pengeluaran (biaya total), rata-rata pendapatan yang diterima petani di Desa Muara Perikan adalah sebesar Rp. 11.026.213/UT atau Rp. 34.852.536/Ha.

Dari Tabel 3 dapat diketahui rata-rata $\mathrm{R} / \mathrm{C}$ ratio usahatani brokoli di Desa Muara Perikan adalah sebesar 3,56 per. Hasil R/C ratio lebih dari satu menunjukkan bahawa usahatani yang dilakukan petani di daerah penelitian telah efisien dan ini juga berarti bahwa usahatani tersebut telah menguntungkan. Nilai R/C ratio 3,56 per usahatani berarti setiap pengeluaran Rp. 1.000 .000 per usahatani akan mendapatkan penerimaan sebanyak Rp. 3.560.000.

\section{Analisa Pemasaran}

Brokoli yang dihasilkan oleh petani Desa Muara Perikan seluruhnya dijual ke pasar atau kepada para pedagang pengumpul. Pedagang pengumpul tersebut biasanya membeli langsung ke lahan petani atau ke rumah-rumah petani sehingga petani tidak perlu mengeluarkan ongkos pemasaran. Pemasaran brokoli ini melalui beberapa saluran pemasaran dan para pelaku pemasaran agar brokoli sampai ke tangan konsumen akhir. Pada pemasaran brokoli terdapat tiga saluran pemasaran yaitu:

\footnotetext{
I. Petani $\rightarrow$ Pedagang Pengumpul Desa $\rightarrow$ Pedagang Pengecer I $\rightarrow$ Konsumen.

II. Petani $\rightarrow$ Pedagang Pengumpul Desa $\rightarrow$ Pedagang Pengecer I $\rightarrow$ Pedagang Pengecer II $\rightarrow$ Konsumen.

III. Petani $\rightarrow$ Pedagang Pengumpul Desa $\rightarrow$ Pedagang Luar Daerah $\rightarrow$ Konsumen.
}

Penelitian ini akan membahas saluran pemasaran I dan II. Hal ini dikarenakan pada saluran pemasaran III, pedagang pengumpul desa akan 
mengirim produknya ke luar daerah Pagaralam (Palembang dan Lahat), karena peneliti mempunyai keterbatasan waktu, biaya dan tenaga.

Dari PPD, sebagian besar disalurkan atau dijual kepada pedagang luar daerah (Palembang dan Lahat) sebanyak 97,56 persen dari keseluruhan brokoli atau sebanyak 42.600 kilogram. Selanjutnya sisa 2,44 persen atau 1.065 kilogram,disalurkan kepada pedagang pasar atau pedagang pengecer I. Pedagang pengecer I menyalurkan brokoli tersebut kepada konsumen dan pedagang pengecer II. Sebanyak 1,78 persen dari keseluruhan awal disalurkan kepada konsumen dan 0,66 persen sisanya disalurkan kepada pedagang pengecer II. Hingga akhirnya pedagang pengecer II menjual brokoli tersebut kepada konsumen.

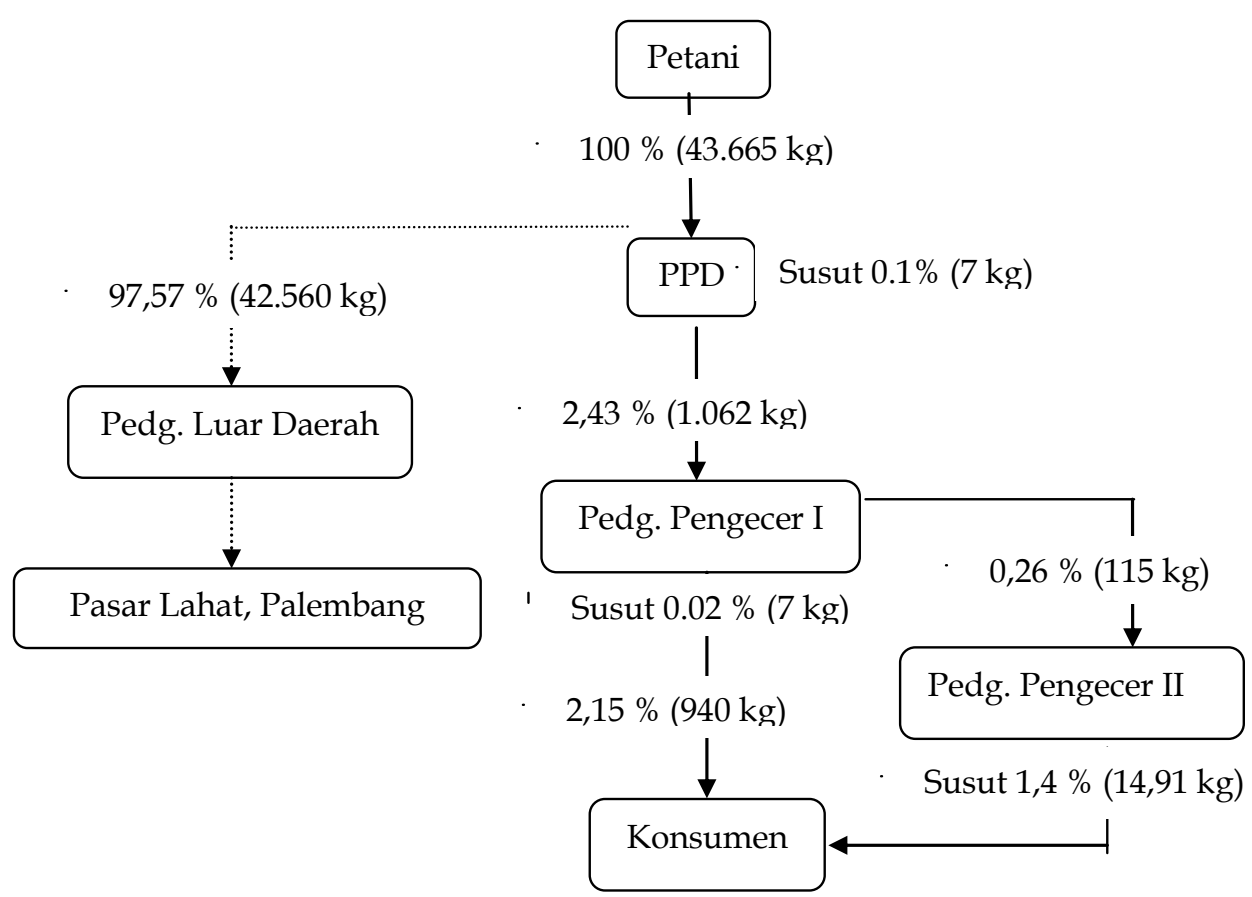

Gambar 1. Saluran Pemasaran Brokoli di Desa Muara Perikan

Marjin pemasaran merupakan selisih harga yang dibayarkan ke produsen dan harga yang diberikan konsumen. Besarnya marjin pemasaran brokoli pada kedua saluran pemasaran dan penyebarannya dapat dilihat pada Tabel 4. 
Tabel 4. Analisis Marjin Pemasaran Brokoli

\begin{tabular}{|c|c|c|c|c|}
\hline \multirow[b]{2}{*}{ Uraian } & \multicolumn{2}{|l|}{ Saluran I } & \multicolumn{2}{|c|}{ Saluran II } \\
\hline & $\begin{array}{l}\text { Harga rata-rata } \\
(\mathrm{Rp} / \mathrm{Kg})\end{array}$ & $\begin{array}{c}\text { Share } \\
(\%)\end{array}$ & $\begin{array}{l}\text { Harga rata-rata } \\
(\mathrm{Rp} / \mathrm{Kg})\end{array}$ & $\begin{array}{c}\text { Share } \\
(\%)\end{array}$ \\
\hline 1. Petani & & & & \\
\hline - Harga Jual & $6.000,00$ & 66,67 & $6.000,00$ & 51,43 \\
\hline 2. Pedg. Pengumpul Desa & & & & \\
\hline - Harga Beli & $6.000,00$ & 66,67 & $6.000,00$ & 51,43 \\
\hline - B.Transportasi & 120,44 & 1,34 & 120,44 & 1,03 \\
\hline - B. Retribusi & 2,39 & 0,03 & 2,39 & 0,02 \\
\hline - B. Tenaga Kerja & 33 & 0,37 & 33 & 0,28 \\
\hline - B. Pengemasan & 49,98 & 0,56 & 49,98 & 0,43 \\
\hline - B. Sewa Gudang & 30,50 & 0,34 & 30,50 & 0,26 \\
\hline - B. Penystn. Alat & 22,56 & 0,25 & 22,56 & 0,19 \\
\hline - B. Penystn Brokoli & 5,97 & 0,07 & 5,97 & 0,05 \\
\hline - Total Biaya & 264,85 & 2,94 & 264,85 & 2,27 \\
\hline - Marjin & $1.000,00$ & 11,11 & $1.000,00$ & 8,57 \\
\hline - Profit Marjin & 735,15 & 8,17 & 735,15 & 6,30 \\
\hline - Harga Jual & $7.000,00$ & 77,78 & $7.000,00$ & 59,99 \\
\hline 3. Pedg. Pengecer I & & & & \\
\hline - Harga Beli & $7.000,00$ & 77,78 & $7.000,00$ & 59,99 \\
\hline - B. Transportasi & 134,00 & 1,48 & 134,00 & 1,15 \\
\hline - B. Kantong Plastik & 30,00 & 0,33 & 30,00 & 0,26 \\
\hline - B. Sewa Lapak & 101,73 & 1,13 & 101,73 & 0,87 \\
\hline - B. Penystn Alat & 114,28 & 1,27 & 114,28 & 0,98 \\
\hline - B. Retribusi & 12,95 & 0,14 & 12,95 & 0,11 \\
\hline - B. Penystn. Brokoli & 46,93 & 0,52 & 46,93 & 0,4 \\
\hline - Total Biaya & 439,89 & 4,89 & 439,89 & 3,77 \\
\hline - Marjin & 2000,00 & 22,22 & 2000,00 & 17,14 \\
\hline - Profit Marjin & $1.560,11$ & 17,33 & $1.560,11$ & 13,37 \\
\hline - Harga Jual & $9.000,00$ & 100,00 & $9.000,00$ & 77,14 \\
\hline 4. Pedg. Pengecer II & & & & \\
\hline - Harga Beli & - & - & $9.000,00$ & 77,14 \\
\hline - B. Transportasi & - & - & 94,14 & 0,81 \\
\hline - B. Kantong Plastik & - & - & 27,14 & 0,23 \\
\hline - B. Penystn. Alat & - & - & 50,08 & 0,43 \\
\hline - B. Penystn. Brokoli & - & - & 117,50 & 1,01 \\
\hline - Total Biaya & - & - & 288,86 & 2,46 \\
\hline - Marjin & - & - & $2.666,67$ & 22,86 \\
\hline - Profit Marjin & - & - & $2.377,81$ & 20,38 \\
\hline - Harga Jual & - & - & $11.666,67$ & 100,00 \\
\hline Total Biaya Pemasaran & 704,74 & 7,83 & 993,60 & 8,51 \\
\hline Total Profit & $2.295,26$ & 25,50 & $4.673,07$ & 40,05 \\
\hline Total Marjin & $3.000,00$ & 33,33 & $5.666,67$ & 48,57 \\
\hline
\end{tabular}

Ket: *) Persentase Terhadap harga Jual Pedagang akhir.

Dari Tabel 4 ini dapat dilihat bahwa pada saluran pemasaran I farmer sharenya 66,67 persen, ini berarti bagian yang diterima petani atau harga yang diterima petani cukup tinggi. Marjin pemasarannya sebesar Rp. 3000 per kilogramnya dengan keuntungan pemasaran Rp.2.295,26 per kilogramnya. Pada saluran pemasaran II, nilai farmer share lebih kecil yaitu sebesar 51,43 persen dengan marjin pemasaran sebesar Rp. 5.666,67 dan keuntungan pemasaran sebesar Rp. 4.673,07 per kilogramnya.

Hasil analisis marjin yang telah dilakukan dapat diketahui bahwa total marjin pemasaran yang terjadi pada saluran I adalah sebesar Rp. 3000 per 
kilogram atau 33,33 persen dari harga jual pedagang pengecer pasar. Sedangkan pada saluran II total marjin pemasaran sebesar Rp. 5.666,67 per kilogram atau 48,57 persen dari pedagang pengecer II. Besarnya marjin pemasaran yang terjadi pada saluran II disebabkan pada saluran II lebih banyak melibatkan lembaga pemasaran, sehingga akan terjadi rantai pemasaran yang panjang. Dengan demikian biaya dan keuntungan pemasaran yang diambil akan lebih besar.

Pada saluran II tersebut, marjin pemasaran terbesar terjadi pada pedagang pengecer II yaitu sebesar Rp. 2.666,67 per kilogramnya. Sedangkan pada saluran I sebesar Rp. 2000 per kilogram atau 22,22 persen dari harga jual pengecer pasar. Besarnya marjin pemasaran ini disebabkan karena banyaknya keuntungan yang di ambil oleh pedagang pengecer II, sementara komponen biayanya tidak terlalu banyak dibandingkan pedagang pengecer I. Marjin pemasaran terkecil terdapat pada PPD yaitu sebesar Rp. 1000 atau 11,11 persen dari harga jual pedagang pengecer I untuk saluran pemasaran I dan 8,57 persen dari harga jual pedagang pengecer II pada saluran pemasaran II.

Untuk mengetahui marjin pemasaran, biaya pemasaran merupakan hal yang penting. Biaya pemasaran yang dimaksudkan adalah biaya-biaya yang digunakan untuk penyaluran brokoli dari petani hingga ke konsumen akhir (konsumen rumah tangga). Mengenai biaya pemasaran tersebut dapat dilihat pada Tabel 5.

Tabel 5. Penyebaran Biaya Pemasaran Brokoli

\begin{tabular}{lrrrrrr}
\hline \multirow{2}{*}{ Komponen Biaya } & \multicolumn{3}{c}{ Saluran Pemasaran I } & \multicolumn{2}{c}{ Saluran Pemasaran II } \\
\cline { 2 - 7 } & $\mathrm{Rp} / \mathrm{Kg}$ & $\left.\%^{*}\right)$ & $\left.\%{ }^{* *}\right)$ & $\mathrm{Rp} / \mathrm{Kg}$ & $\left.\%{ }^{*}\right)$ & $\left.\%{ }^{* *}\right)$ \\
\hline - B. Transportasi & 254,44 & 2,83 & 36,10 & 348,58 & 2,98 & 35,08 \\
- B. Retribusi & 15,34 & 0,17 & 2,18 & 15,34 & 0,13 & 1,54 \\
- B. Tenaga Kerja & 33 & 0,37 & 4,68 & 33 & 0,28 & 3,32 \\
- B. Sewa Gudang/Lapak & 132,23 & 1,47 & 18,76 & 132,23 & 1,13 & 13,31 \\
- B. Pengemasan & 49,98 & 0,56 & 7,09 & 49,98 & 0,43 & 5,03 \\
- B. Kantong Plastik & 30,00 & 0,33 & 4,26 & 57,14 & 0,48 & 5,75 \\
- B. Penystn. Alat & 136,84 & 1,52 & 19,42 & 186,92 & 1,60 & 18,81 \\
- B. Penystn. Brokoli & 52,91 & 0,59 & 7,51 & 170,41 & 1,46 & 17,51 \\
\hline \multicolumn{1}{c}{ Jumlah } & 704,74 & 7,83 & 100,00 & 993,60 & 8,51 & 100,00 \\
\hline \multicolumn{1}{c}{ Kuyyyyy}
\end{tabular}

Ket : *) persentase terhadap harga jual pedagang akhir

**) persentase terhadap total biaya pemasaran

Terdapat biaya-biaya yang dikeluarkan oleh setiap lembaga pemasaran dan biaya yang tidak dikeluarkan oleh setiap lembaga pemasaran. Pada saluran I total biaya transportasi yang dikeluarkan sebesar Rp. 254,44 per kilogram atau 36,10 persen dari total biaya pemasaran, sedangkan untuk saluran pemasaran II sebesar Rp.348,58 per kilogram atau 35,08 persen dari total biaya pemasaran. Baik saluran pemasaran I maupun saluran II biaya transportasi terbesar ditanggung oleh PPD, hal ini disebabkan untuk mengumpulkan brokoli dari lahan hingga ke tempat pengumpul membutuhkan waktu yang cukup lama sehingga biaya transportasi pun akan semakin besar. 
Untuk biaya penyusutan alat pada saluran I adalah sebesar Rp. 136,84 per kilogram atau 19,42 persen dari total biaya pemasaran. Pada saluran II biaya penyusutan alat sebesar Rp.186,92 per kilogramnya atau sebesar 18,81 persen dari total biaya pemasaran. Untuk biaya penyusutan brokoli secara keseluruhan pada saluran I sebesar Rp. 52,91 per kilogram atau 7,51 persen dari total biaya pemasaran, sedangkan saluran II sebesar Rp. 170,41 atau sebesar 17,51 persen dari total biaya pemasaran. Penyusutan brokoli terbesar terjadi pada pedagang pengecer I dan pengecer II, hal ini disebabkan karena tidak adanya sortasi terhadap brokoli yang mereka beli.

Untuk biaya retribusi, tenaga kerja, sewa gudang/lapak, pengemasan, serta biaya kantong plastik merupakan biaya-biaya yang dikeluarkan oleh lembaga pemasaran tertentu saja. Pada saluran pemasaran I, secara keseluruhan biaya retribusi adalah sebesar Rp. 15,34 per kilogram atau sebesar 2,18 persen dari total biaya pemasaran. Biaya tenaga kerja sebesar Rp. 33 per kilogram, dan biaya sewa gudang/lapak sebesar Rp. 132,23 per kilogram, biaya pengemasan Rp 49,98 per kilogram, serta biaya kantong plastik sebesar Rp.30 per kilogramnya atau 4,26 persen dari keseluruhan biaya pemasaran pada saluran I.

Tabel 6. Penyebaran Keuntungan Pemasaran Brokoli

\begin{tabular}{|c|c|c|c|c|c|c|}
\hline \multirow{2}{*}{ Lembaga Pemasaran } & \multicolumn{3}{|c|}{ Saluran Pemasaran I } & \multicolumn{3}{|c|}{ Saluran Pemasaran II } \\
\hline & $\mathrm{Rp} / \mathrm{Kg}$ & $\left.\%{ }^{*}\right)$ & $\% * *)$ & $\mathrm{Rp} / \mathrm{Kg}$ & $\left.\% *{ }^{*}\right)$ & $\% * *)$ \\
\hline - PP Desa & 735,15 & 8,17 & 32,03 & 735,15 & 6,30 & 15,73 \\
\hline - $\quad$ Pedagang Pengecer I & $1.560,11$ & 17,33 & 67,97 & $1.560,11$ & 13,37 & 33,39 \\
\hline Pedagang Pengecer II & - & - & - & $2.377,81$ & 20,38 & 50,88 \\
\hline Jumlah & $2.295,26$ & 25,50 & 100,00 & $4.673,07$ & 40,05 & 100,00 \\
\hline
\end{tabular}

Sumber: Data primer 2012, diolah

Ket : *) persentase terhadap harga jual pedagang akhir

**) persentase terhadap total biaya pemasaran

Pada saluran II biaya retribusi, tenaga kerja, sewa gudang/lapak, dan biaya pengemasan yang dikeluarkan sama besar dengan saluran I hanya saja secara persentase terhadap total biaya pemasaran berbeda. Untuk biaya retribusi 1,54 persen, biaya tenaga kerja 3,32 persen, biaya sewa gudang/lapak sebesar 13,31 persen, dan biaya pengemasan 5,03 persen dari total biaya pemasaran di saluran II. Untuk biaya kantong plastik terjadi perbedaan antara saluran I dan saluran II, hal ini dikarenakan pedagang pengecer II pun mengeluarkan biaya ini, pada saluran II ini biaya kantong plastik yang dikeluarkan sebesar Rp. 57,14 per kilogram atau 5,75 persen dari keseluruhan biaya pemasaran di saluran II.

Keuntungan pemasaran merupakan selisih antara harga jual dengan biaya-biaya yang dikeluarkan oleh masing-masing lembaga pemasaran. Keuntungan lembaga pemasaran pada saluran I adalah sebesar Rp. 2.295, 26 per kilogramnya atau sebesar 25,5 persen dari harga jual pedagang akhir. Sedangkan pada saluran pemasaran II besarnya keuntungan lembaga pemasaran yang diambil adalah sebesar RP. 4.673,07 per kilogram atau sebesar

184 | Denny Wijaya, Satria Putra Utama Dan Indra Cahyadinata. Analisis ... 
40,05 persen dari harga jual di tingkat pedagang akhir. Penyebaran dan besarnya keuntungan pemasaran menurut lembaga pemasaran dapat dilihat pada Tabel 7.

Keuntungan pemasaran terbesar diperoleh oleh pedagang pengecer II yaitu sebesar Rp. 2.377,81 per kilogram atau 50,88 persen dari total keuntungan di saluran II. Keuntungan pemasaran terkecil diperoleh oleh PPD yaitu sebesar Rp. 735,15 per kilogram atau 32,03 persen dari total keuntungan di saluran I. Untuk saluran II, keuntungan pemasaran yang diperoleh PPD adalah 15,73 dari total keuntungan pemasaran.

Berdasarkan rasio keuntungan, nilai $\Pi / C$ untuk saluran pemasaran pertama adalah 3,26 dan saluran merketing kedua adalah 4,70. Dalam hal keuntungan, saluran kedua terlihat lebih efisien dari saluran pertama, tetapi dari nilai share petani dan harga tingkat konsumen, saluran pertama dapat dikatakan lebih efisien.

\section{SIMPULAN DAN SARAN}

\section{Simpulan}

Dari hasil penelitian mengenai analisis pendapatan dan pemasaran brokoli di Desa Muara Perikan Kecamatan Pagaralam Selatan, didapat kesimpulan bahwa:

1. Usahatani brokoli di Desa Muara Perikan telah efisien, dengan ratio antara penerimaan dan total biaya sebesar 3,56. Dengan rata-rata total biaya Rp. Rp. 15.920.943/Ha dan rata-rata total penerimaan sebesar Rp. 55.121.397/Ha, maka diketahui rata-rata pendapatan petani brokoli adalah sebesar Rp. 34.852.536/Ha.

2. Terdapat tiga lembaga pemasaran utama dalam sistem pemasaran brokoli, untuk saluran pemassaran III dilakukan pada pedagang luar daerah dengan persentase penjualan 97,57 persen dari total $43.665 \mathrm{~kg}$ brokoli yang dipasarkan. Untuk saluran I dan II, diidentifikasi saluran I lebih efisien dibandingkan saluran pemasaran II. Proporsi share untuk petani 66,67 persen sementara untuk saluran II sebesar 52,43 persen.

3. Marjin pemasaran terbesar terjadi pada saluran III sebesar Rp. $5.667 / \mathrm{kg}$ atau 48,57 persen dari seluruh kegiatan pemasaran di saluran III. Proporsi marjin terbesar diperoleh oleh pedagang pengecer II sebesar Rp. 2.667 atau 22,86 persen. Untuk saluran II, total marjin yang diperoleh sebesar Rp. 3000/kg atau 33,33 persen dari seluruh kegiatan pemasaran di saluran II dengan keuntungan terbesar diperoleh oleh pedagang pengecer I sebesar Rp. 1.560 atau 17,33 persen.

\section{Saran}

Mulsa merupakan biaya input terbesar yang dikeluarkan oleh petani. Dinas pertanian setempat seharusnya bisa memberi informasi kepada petani 
brokoli dalam hal penggunaan mulsa tersebut agar biaya yang digunakan untuk mulsa bisa diminimkan.

\section{DAFTAR PUSTAKA}

Anindita, R. 2004. Pemasaran Hasil Pertanian. PAPYRUS: Surabaya.

Biro Pusat Statistik. 2009. Pagar Alam dalam Angka. (Online) (Diakses 29 Desember 2011) tersedia di World Wide Web: http:/ / www.bps.pagaralam.go.

Lubis, F. 2007. Analisis Permintaan dan Efisiensi Pemasaran Sawi Pahit Pada Tingkat Pedagang Pengecer di Kota Bengkulu. Skripsi. Jurusan Sosial Ekonomi Pertanian,Fakultas Pertanian, Universitas Bengkulu (tidak dipublikasikan).

Mubyarto. 1989. Pengantar Ekonomi Pertanian. LP3ES, Jakarta.

Soekartawi. 1995. Analisis Usahatani. UI-Press, Jakarta. 